Research Article

\title{
Laminated Glass Cantilevered Plates under Static and Impact Loading
}

\author{
Luigi Biolzi (iD, ${ }^{1}$ Antonio Bonati, ${ }^{2}$ and Sara Cattaneo ${ }^{1,2}$ \\ ${ }^{1}$ Dipartimento di Architettura, Ingegneria delle Costruzioni e Ambiente Costruito, Politecnico di Milano, Milano, Italy \\ ${ }^{2}$ Construction Technologies Institute, Italian National Research Council (ITC-CNR), San Giuliano Milanese, Milan, Italy \\ Correspondence should be addressed to Luigi Biolzi; luigi.biolzi@polimi.it
}

Received 31 January 2018; Revised 16 April 2018; Accepted 9 May 2018; Published 25 June 2018

Academic Editor: Victor Yepes

Copyright (c) 2018 Luigi Biolzi et al. This is an open access article distributed under the Creative Commons Attribution License, which permits unrestricted use, distribution, and reproduction in any medium, provided the original work is properly cited.

The structural performance of cantilevered laminated glass plates for different glass thicknesses and interlayers is considered in this paper. Heat-strengthened and tempered glass plies and two different interlayer films were utilized. The response of laminated glass specimens is then evaluated under low-velocity hard and semirigid impacts. Experimental findings were simulated and discussed by means of finite element analyses. In particular, this discussion includes the evaluation of the influence that the fixed edge clamping technique (number of clamps, their size, and their stiffness) has on the stress distribution in the specimens.

\section{Introduction}

Over the past decades, as a consequence of the increasing architectural preferences, glass is used not only for secondary elements of the buildings but also for their main load-carrying members such as beams, floor plates, or columns. The mechanical resistance of these members is an essential characteristic with direct impact on safety [1]. This application of glass is now realistic because glass plies of significant strength have become available and structural members that satisfy the required strength performance can be designed [2]. Indeed, in addition to nontreated annealed glass that breaks under tensile stresses much lower than $100 \mathrm{~N} / \mathrm{mm}^{2}$, there are heattreated glasses characterized by a surface layer with substantial residual compressive stresses which enhance their overall mechanical characteristics. In particular, heat-strengthened and tempered glasses show enhanced tensile strength due to surface-compressive prestress [3]. The failure of currently produced glass is controlled by the presence of surface defects caused by industrial production processes and, as a consequence, the strength of such glass is correlated with a statistical distribution of those defects [4-6].

A safe design requires structures without the risk of catastrophic collapse [7]. To achieve that, in addition to permanent and variable loads, it is necessary to consider the effects caused by temperature changes, to which glass is particularly sensitive due to its brittleness [8]. For the same reason, when employed for structural reasons, glass members are typically laminated (LG). They are composed of two or more glass layers bonded by one or more polymeric film interlayers, which play a fundamental role both in the prepeak and postfailure behavior. This is so because the adhesion to the interlayer prevents glass fragments from scattering in the event of a glass ply failure. Indeed, the interlayer goes into tension and maintains the glass element in place. The most widely used polymeric films for glass lamination are polyvinyl butyral (PVB), ethylene vinyl acetate (EVA), and ionoplast sentryGlas (SG) [9-13]. Pure PVB necessitates the addition of softeners which provides plasticity and toughness. The properties of EVA vary from partial crystalline and thermoplastic to amorphous and rubberlike, but an increased volume of vinyl acetate improves strength and ultimate elongation. SG is an ionoplast polymer primarily composed of ethylene/methacrylic acid copolymers with minor amounts of metal salts. Compared with PVB, ionoplast SG reveals both higher stiffness and strength and then an enhanced structural performance. In any case, due to viscoelasticity of the polymer interlayer film, the mechanical response of a laminated glass member is substantially influenced by loading duration and temperature. In the undamaged range, the laminated glass behavior depends on the stiffness of the 
polymer film and can vary between a monolithic glass of equivalent thickness (complete bonding of the glass layers) and the independent glass layers (shearless sliding of the glass layers) [12]. The type of interlayer is therefore of crucial importance in the undamaged glass phase (e.g., $[11,12])$ and in the postfailure phase $[9,11,14-18]$. When glass fails and is unable to bear tensile stresses, both the interlayer's tensile strength and stiffness are needed to provide significant residual load carrying capacity. For damaged LG structural elements, the increase in the volume of a broken tempered glass layer generates two competing effects in the undamaged glass layers influencing the residual carrying capacity [15]. One is a positive "tension stiffening" occurring over time and the other is development of the "negative" stress/strain fields in undamaged glass layers.

In this paper, the response of two-layer laminated cantilever glass panels (which in modern construction is frequently used as balustrade) is experimentally investigated $[16,19]$ on the basis of the recommendations of Italian design code and standards [20-22]. A cantilevered plate is critical in the joint: it must be carefully realized to avoid a severe reduction of the load carrying capacity.

After a concise introduction to the European standard framework [23-26] that highlights the unclear and ambiguous characterization procedure of balustrade, static and impact loading tests were performed on LG plates with different glass ply thicknesses and interlayer films. The static and dynamic experimentally obtained responses are compared with those resulting from the numerical (finite element) analysis in which the actual clamping technique was modeled employing its actual geometrical features. In particular, for the infill panels, numerical simulations were conducted to investigate the effects of the number of clamps at the fixed edge of the plate, their size, and their stiffness, as well as to investigate the stress concentrations which are hard to quantify in the experiments.

\section{Standard Framework}

There are more than one hundred EN standards related to glass in buildings, about 20 of them are harmonized standards. In addition to these, there are harmonised technical specifications that refer to products and systems with glass elements, such as curtain walls, doors and windows, internal partition kits, structural sealant glazing kits (SSGK), and more are under development.

For the time being, no glass elements or products are covered by harmonised standards taking into account some essential characteristics related to the first basic requirements for construction works (BWR1) "mechanical resistance and stability" as defined in Annex I of Regulation (EU) No 305/2011 of the European Parliament and of the Council of 9 March 2011 [23] laying down harmonised conditions for the marketing of construction products and repealing Council Directive 89/106/ECC. Commission Decision 2000/245/EC of 2 February 2000, from which the harmonised standards on glass products are derived, relating to flat glass, profiled glass, and glass block products, does not consider load-bearing applications and because of this, the BWR1 is not considered. In our opinion, also the "mechanical" essential characteristics for glass cantilevered railings or balustrades are related to BWR4 "safety and accessibility in use" as it is the case for facades where no other fall protection system is provided other than the glass infill panel. Therefore, attention should be paid to this subject and a rigorous technicalscientific approach should be conducted to determine the characteristics of these products whose collapse might be a serious danger to the safety of people.

The only apparent formal distinction between BWR1 and BWR4 can instead have an influence on the definition of assessment and verification of constancy of performance (AVCP) of products in relation to their essential characteristics in accordance with the systems set out in Annex V to Regulation (EU) 305/2011 [23] directly affecting the cost to be incurred by manufacturers.

A number of European Assessment Documents (EADs), the documents adopted by the organization of Technical Assessment Body (TAB) for the purpose of issuing European Technical Assessments (ETAs), are currently under development. The most advanced document relates to "cantilevered structural glass railing/balustrade" (EAD 090040-00-0404 [24]): it has been at EOTA adoption level since 25.02.2016. It was stopped because in accordance with Article 28 and 60 of Regulation (EU) 305/2011 [23], the commission is developing a specific Delegated Decision on AVCP system. In this regard, there is currently only one draft document, which has not been adopted or endorsed by EC, representing the preliminary views of the commission services referring to balustrade kits and railing kits to be used in construction works solely to prevent falls and not submitted to vertical loads from the structure. This document would seem to be aimed at defining the AVCP system as a function of the horizontal loads applied to the products. When the products, under their intended use, are subjected to horizontal loads lower than the established load level, the assessment of their performance regarding all essential characteristics, except reaction to fire, should be carried out by the manufacturer; in the other cases (horizontal loads greater than the established level), the assessment should be carried out by a third party.

The draft EAD "cantilevered structural glass railing/ balustrade" [24] identifies the essential mechanical characteristics as "resistance and stability to wind and horizontal load" and "impact resistance" and it refers to EN standards as far as assessment methods and criteria are concerned.

In May 2017, a UNI Standard was published at the Italian national level. It is the voluntary test standard UNI 11678 Glass in Building-Glass Infill Elements with Fall Protection Function-Resistance to Linear Static Load and Dynamic Load-Test Methods [21]. This National standard represents a good reference including in a systematic way, for different product families, test setups, test methods, and test sequences to assess the glass balustrades.

The test methods are carried out to determine resistance to static and dynamic impact loads. Static horizontal loads are assessed in terms of serviceability limit state (SLS), ultimate limit state (ULS), and collapse limit state (CLS). The CLS represents the product resistance to horizontal loads also in case of partial damage/failure of any arbitrary glass pane within the balustrade. 


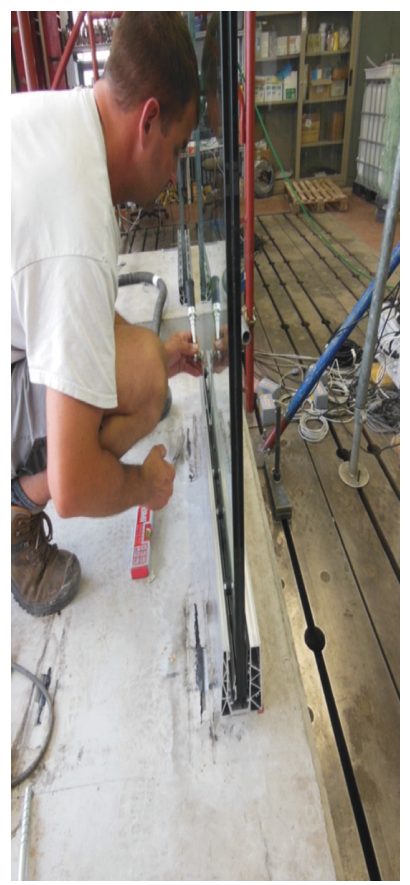

(a)

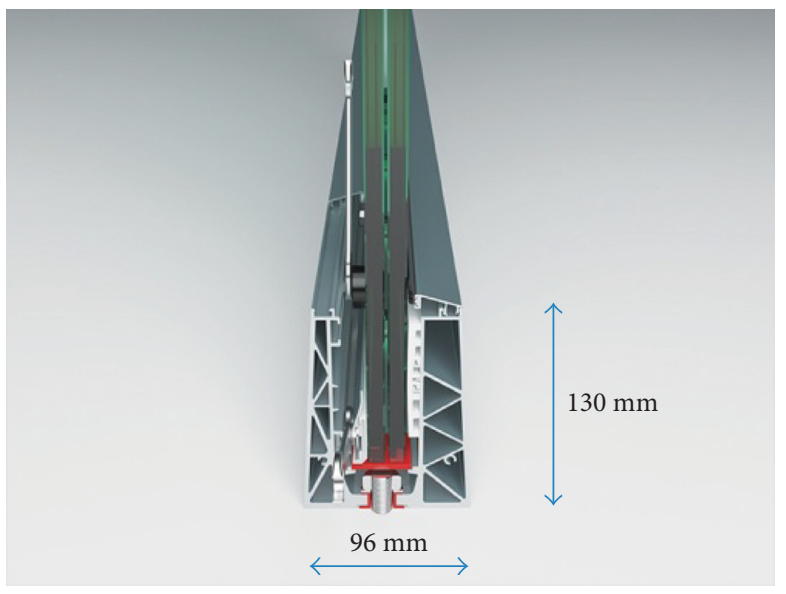

(b)

Figure 1: Profile installed on the concrete slab.

TABle 1: Performed tests.

\begin{tabular}{|c|c|c|c|c|c|c|c|}
\hline Number & Specimen & Glass thickness $(\mathrm{mm})$ type & Interlayer thickness $(1.52 \mathrm{~mm})$ & Glass length $(\mathrm{m})$ & $S$ & $\mathrm{HB}$ & SR \\
\hline 1 & NF4-8T-8I-PVB & $8 \mathrm{~T}-8 \mathrm{I}$ & PVB & 1 & $x$ & & \\
\hline 2 & NF4-10T-10I-PVB & $10 \mathrm{~T}-10 \mathrm{I}$ & PVB & 1 & $x$ & & \\
\hline 3 & NF4-10T-10T-SG & $10 \mathrm{~T}-10 \mathrm{~T}$ & SG & 1 & $x$ & & \\
\hline 4 & NF4-8T-8I-PVB & $8 \mathrm{~T}-8 \mathrm{I}$ & PVB & 1 & & $x$ & $x$ \\
\hline 5 & NF4-10T-10I-PVB & $10 \mathrm{~T}-10 \mathrm{I}$ & PVB & 1 & & $x$ & $x$ \\
\hline 6 & NF4-10T-10T-SG & $10 \mathrm{~T}-10 \mathrm{~T}$ & SG & 0.5 & & $x$ & $x$ \\
\hline
\end{tabular}

S: static; HB: hard body; SR: semirigid; x: conducted test.

The results of these tests are also useful to develop and calibrate models for the calculation analysis. More details about the design methods of glass elements and products can be found in the document "Guidelines for European Standard Structural Design of Glass Components" by CEN-TC 250 [25].

\section{Materials and Test Setup}

The experimental program included static and impact tests according to the Italian standard [21].

Tests were conducted on cantilevered glass plates, commonly used as balustrade, where the constrained edge was realized with an aluminum profile (defined NF4) which retain the installed plates as shown in Figure 1. For these plates, the principal components of loading are lateral forces due to horizontal loads of a short duration.

Three types of laminated glass plates (width $1 \mathrm{~m}$, height $1.1 \mathrm{~m})$ were considered:

(i) $8 \mathrm{~T}-8 \mathrm{I}-\mathrm{PVB}$ made with tempered and toughened glass plies of $8 \mathrm{~mm}$ bonded through $1.52 \mathrm{~mm}$ PVB interlayer (ii) 10T-10I-PVB made with tempered and toughened glass plies of $10 \mathrm{~mm}$ bonded through $1.52 \mathrm{~mm}$ PVB interlayer

(iii) $10 \mathrm{~T}-10 \mathrm{~T}-\mathrm{SG}$ made with two tempered glass plies of $10 \mathrm{~mm}$ bonded through $1.52 \mathrm{~mm}$ SG interlayer.

For impact tests on LG glass 10T-10T-SG, a specimen with a width of $0.5 \mathrm{~m}$ was considered.

Table 1 summarizes the performed tests.

The base rail is a kit made of metallic profile, plastic and metallic elements (adjusting screws), and gaskets. First, the base rail was installed on a concrete slab of concrete class C20/25 (cast according to TR048 [26]) with 5 concrete screws, diameter $12 \mathrm{~mm}$ (hole depth $160 \mathrm{~mm}$, tightening torque $80 \mathrm{Nm}$, and spacing $20 \mathrm{~cm}$ ) (Figure 1). The average cubic compressive strength was $35.1 \mathrm{MPa}$. The anchors edge distance was $150 \mathrm{~mm}$.

The LG plate was held inside the profile by some adjusting screws (Figure 1) placed both in the upper (N. 5 for static test and N. 3 for dynamic test on glass 10T-10T-SG) and in the lower (N. 7 for static test and N. 4 for dynamic test on glass $10 \mathrm{~T}-10 \mathrm{~T}-\mathrm{SG}$ ) part of the profile. 


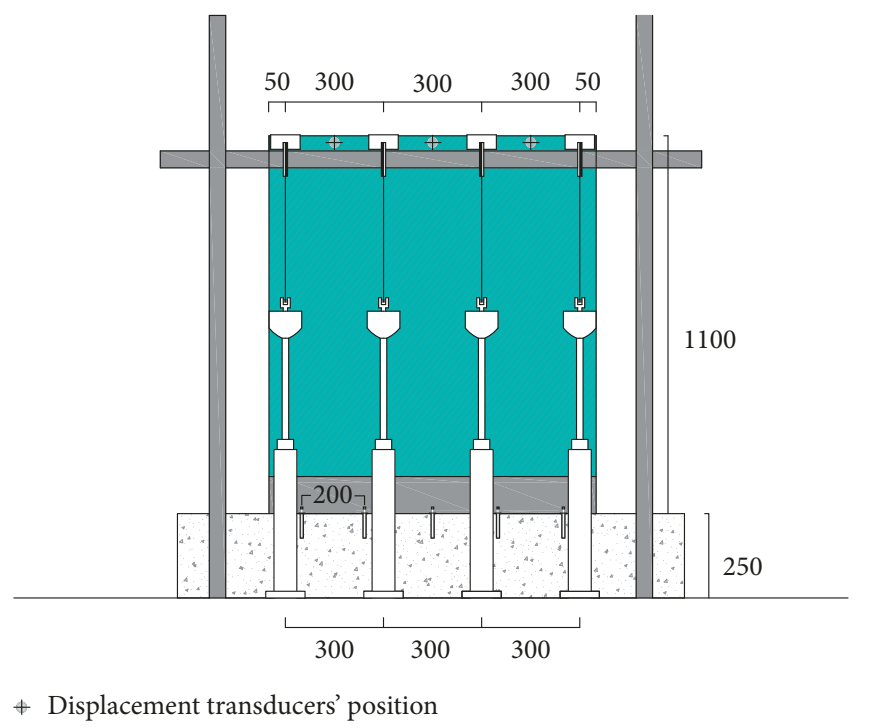

(a)

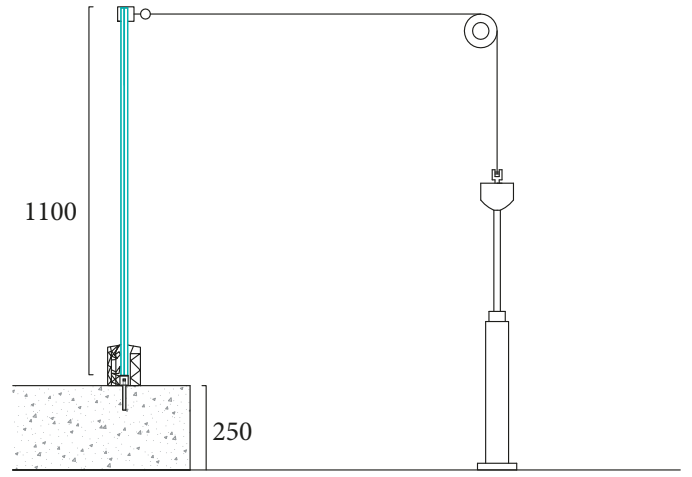

(b)

Figure 2: Sketch of the testing system (static test): front and lateral view (measure in $\mathrm{mm}$ ).

The adjusting screws were tightened with the calibrated torque wrench with a tightening torque of $6.5 \mathrm{Nm}$. Once the LG plate was positioned so that tempered glass was subjected to load/impact tests, the tests were conducted.

The average temperature and the relative humidity of the laboratory during the tests were equal to $28.6^{\circ} \mathrm{C}$ and $51 \%$, respectively.

3.1. Static Test. The tests were performed with a loading system made of four pneumatic jacks attached to the strong floor that apply the load via four ties attached to the upper edge of the LG plate with spacing of $30 \mathrm{~cm}$. The sketch of the testing system is shown in Figure 2.

The applied load of each jack was monitored via four load cells (class 1 ) acquired by a control system through PLC Siemens S7 with specific software designed to maintain a uniform load in the four points. The displacements were measured with three wire transducers, mounted at the same height of the load application, at midspan and with spacing of $30 \mathrm{~cm}$.

All data (4 load cells and 3 displacement transducers) were acquired by a Spider $8 \mathrm{HBM}$ data acquisition system with a sample frequency of $2 \mathrm{~Hz}$.

The load was applied according to the procedure defined in the Italian standard [26] which defines four steps:

Step 1: preload. A load equal to the $30 \%$ of the serviceability load was applied in a time ranging between 30 and 120 seconds and held for 5 minutes. The load was removed in a time lower than 10 seconds. The displacement transducers were reset.

Step 2: serviceability limit state (SLS). The serviceability load was applied in a time ranging between 10 and 300 seconds and held for 5 minutes. The load was removed in a time lower than 10 seconds. After the load removal, the displacements of the unloaded specimen were acquired for 15 minutes.

Step 3: ultimate limit state (ULS). The ultimate load (equal to the serviceability load multiplied by the safety factor assumed as 1.5) was applied in a time ranging between 10 and 300 seconds and held for 5 minutes. The load was removed in a time lower than 10 seconds.

Step 4: collapse limit state (CLS). The glass ply subjected to the load was damaged with a hammer in the upper corner. The preload was applied and held for 1 minute. The balustrade was unloaded.

\subsection{Impact Tests}

3.2.1. Hard Body Impact Test. The test, according to the Italian standard [21], was performed using a tempered steel ball with a diameter of $63.5 \mathrm{~mm}$ and weight of $1000 \mathrm{~g}$ as an impactor sustained by an inextensible wire with negligible weight according to the reference code. Three impact points were defined according to the sketch shown in Figure 3(a):

Point 1: along the centerline at a distance of $100 \mathrm{~mm}$ from the upper edge of the specimen

Point 2: along the centerline at half height of the element

Point 3: close to the profile.

The impactor was connected at a fixed point at a distance equal to $180 \mathrm{~cm}$ from point $1,225 \mathrm{~cm}$ from point 2 and about $265 \mathrm{~cm}$ from point 3 . The impactor was placed in contact with the selected point with the wire perpendicular to the floor. Then, it is uplifted at a height of $1020 \mathrm{~mm}$ with respect to the rest position. Each point was hit once.

At the end of the test, the glass was visually inspected to check damages and or anomalies. 


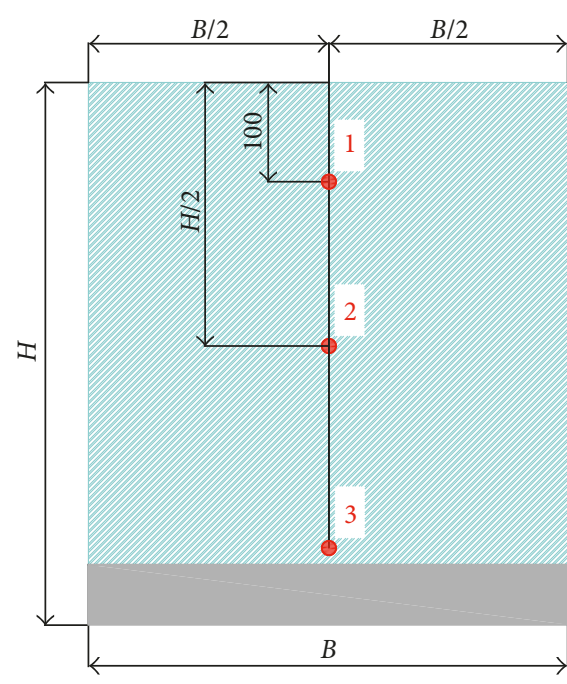

(a)

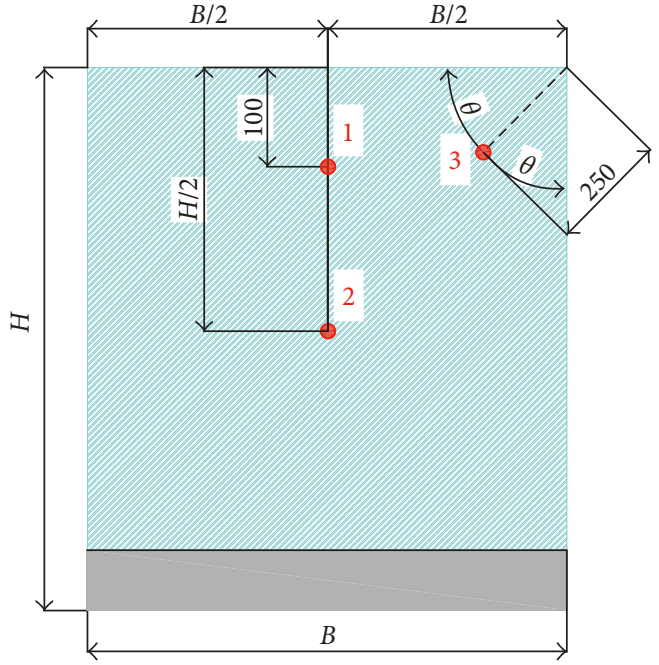

(b)

Figure 3: Impact tests: impact points on the (a) hard body and (b) semirigid body $(H=110 \mathrm{~cm}$ and $B=100 \mathrm{~cm})$.

3.2.2. Semirigid Body Impact Test. The test, according to the Italian standard [21], was performed using an impactor with a mass of $50 \mathrm{~kg}$ according to EN12600 [22] standard. The pressure of the two tires was $0.35 \pm 0.02 \mathrm{MPa}$.

Three impact points have been defined according to the sketch shown in Figure 3(b):

Point 1: along the centerline at a distance of $100 \mathrm{~mm}$ from the upper edge of the specimen

Point 2: along the centerline at half height of the element

Point 3: close to the corner at a distance of $250 \mathrm{~mm}$ along the bisecting line.

The impactor was connected at a fixed point at a distance equal to $180 \mathrm{~cm}$ from point $1,225 \mathrm{~cm}$ from point 2 , and about $188 \mathrm{~cm}$ from point 3 . The impactor was placed in contact with the selected point with the wire perpendicular to the floor. Then, it is uplifted at a height of $1200 \mathrm{~mm}$ with respect to the rest position. Each point was hit once.

At the end of the impact, the glass was visually inspected to check damages and or anomalies.

\section{Experimental Results}

4.1. Static Test. Free-standing glass balustrades must be designed to resist the load as defined in referenced codes of practice. The serviceability load, defined according to Italian Code [20], was assumed equal to $2 \mathrm{kN} / \mathrm{m}$ for glass plies with a thickness of $8 \mathrm{~mm}$ and equal to $3 \mathrm{kN} / \mathrm{m}$ for glass plies with a thickness of $10 \mathrm{~mm}$.

The load-displacement curves reported in Figure 4 highlight that the influence of the glass thickness and of the interlayer on the overall behavior is not negligible. The effect of the settlements of the adjusting screws was removed according to the test procedure defined in the standard [22].

At a load level of $3 \mathrm{kN} / \mathrm{m}$ after five minutes from the application, the average displacement of the specimen
NF4-8T-8I-PVB was about $135 \mathrm{~mm}$, with respect to $85 \mathrm{~mm}$ of NF4-10T-10I-PVB and of $46 \mathrm{~mm}$ of NF4-10T-10T-SG (Table 2). The increase of the displacements after five minutes of the application of the load was limited in all cases but with the same trend: $0.96 \mathrm{~mm}, 0.37 \mathrm{~mm}$, and $0.26 \mathrm{~mm}$ for NF4-8T-8IPVB, NF4-10T-10I-PVB, and NF4-10T-10T-SG, respectively (Figure 5).

In all cases, the tested specimens comply with the standard requirements, namely, the residual displacement and maximum displacement of the serviceability limit state lower than $10 \mathrm{~mm}$ and $100 \mathrm{~mm}$, respectively. Regarding the collapse limit state, the standard prescribes limit values about the load carrying capacity ( $30 \%$ serviceability limit load) and no requirements are suggested about the postfailure response.

4.2. Impact Tests. Tests were performed first with the "hard body" (the steel sphere with a mass of $1 \mathrm{~kg}$ [21] - Figure 6) and then with the "semirigid" body (two tires according to EN12600 [22]).

Whatever the type of glass and the point of , the hard body did not cause any damage.

The semirigid impactor did not cause any damage to glass (Figure 7); however, the profile widened after each impact.

The profiles with a length of $1 \mathrm{~m}$ widened only of about $2 \mathrm{~mm}$, while the profile with a width of $0.5 \mathrm{~m}$ widened of about $7 \mathrm{~mm}$ after the first impact, $6 \mathrm{~mm}$ after the second impact, and $4 \mathrm{~mm}$ after the third impact. Overall, after three impacts, the profile widened of $17 \mathrm{~mm}$ (measured with a caliper).

At the end of the test, the glass was still inside the profile, but it was possible to move it.

\section{Numerical Analysis and Discussion}

In the practical analysis of a cantilevered plate, the joint is considered ideal or perfect. Nevertheless, it does not present uniform stiffness characteristics along the constrained boundary. When significant loads are applied, which may be 


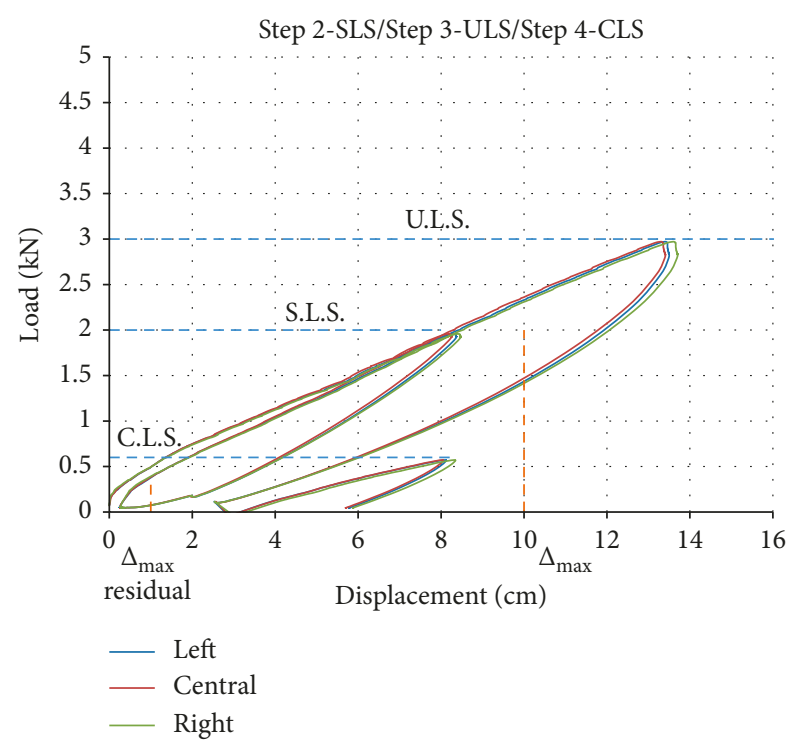

(a)

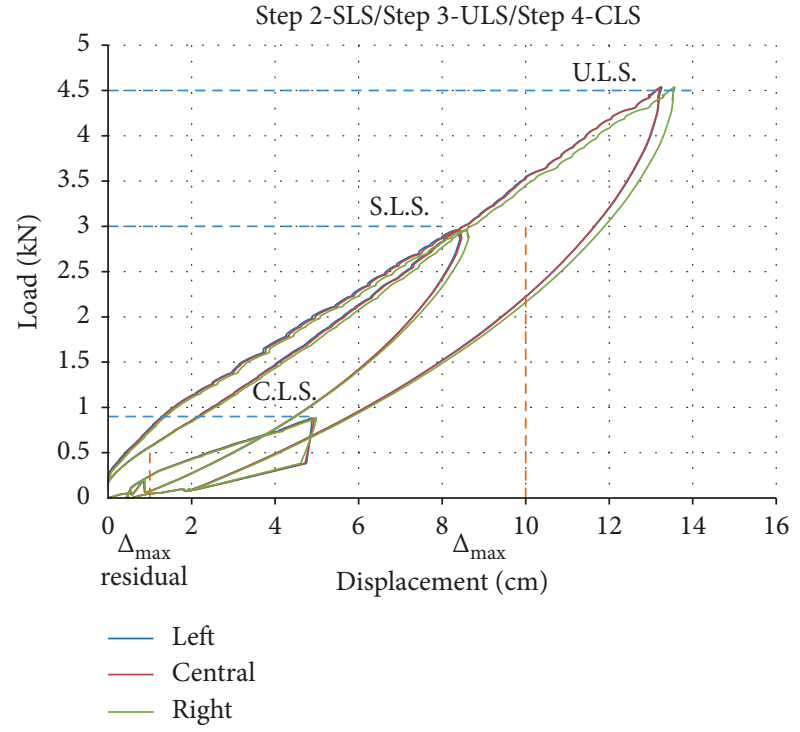

(b)

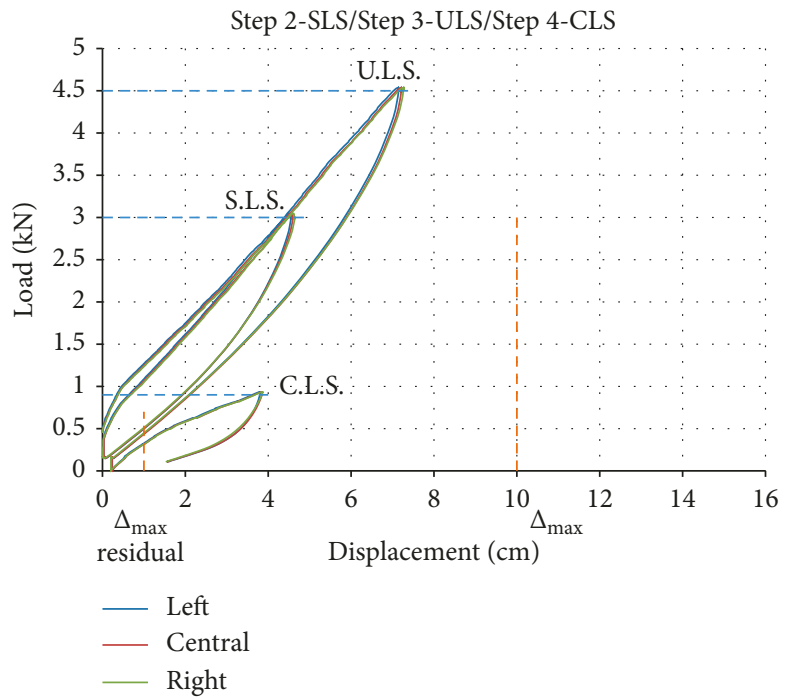

(c)

Figure 4: Load-displacement (three transducers) curves. Specimens: NF4-8T-8I-PVB, NF4-10T-10I-PVB, and NF4-10T-10T-SG.

due to overloadings of the plate, local stress concentrations, which act as critical points of onset of cracking, can appear.

To discuss the experimental response, numerical simulations with the commercial software MEPLA were performed. The software, which is very simple, is a finite element program specifically for static and dynamic computations of glass structures (according to EN12600 [22]). With an automated mesh generation, it presents a variety of calculation possibilities and contemplates different boundary conditions such as point fixing or edge clamping. For the modeling, multilayered plate elements (based on the Mindlin plate theory) are considered. Each node of an n-layered finite element has $4 n+1$ degrees of freedom, where $n$ is the number of layers. The mesh is automatically made by a free meshing algorithm. Only linear elastic analyses can be performed while the viscoelastic behavior is taken into account, assuming a convenient elastic modulus for the
TABLE 2: Displacements at the main load levels.

\begin{tabular}{lccc}
\hline Load level & \multicolumn{3}{c}{ Displacement $(\mathrm{mm})$} \\
& 8T-8I-PVB & 10T-10I-PVB & 10T-10T-SG \\
\hline $2 \mathrm{kN} / \mathrm{m}$ & 82.84 & 49.79 & 25.37 \\
$3 \mathrm{kN} / \mathrm{m}$ & 134.38 & 84.69 & 45.91 \\
$4.5 \mathrm{kN} / \mathrm{m}$ & - & 132.63 & 72.06 \\
\hline
\end{tabular}

interlayer. The dimension and stiffness of clamps in FEA were assumed equal to $30 \mathrm{~mm}$ and $200 \mathrm{~N} / \mathrm{mm}$, respectively. The values of the interlayer elastic modulus used in the numerical analyses was $2 \mathrm{MPa}$. The plate was automatically discretized with elements having an average size of $8 \mathrm{~cm}$. The total number of elements was equal to 504 for a total number of 13,943 degrees of freedom. A mesh refinement with elements having an average size of $2 \mathrm{~cm}$ was considered. 


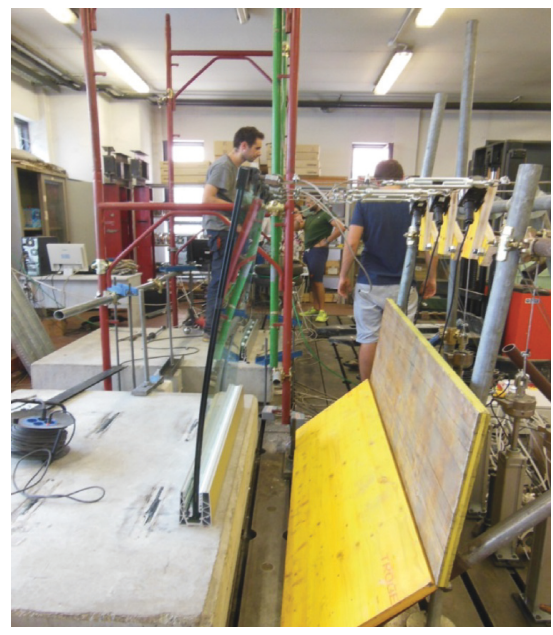

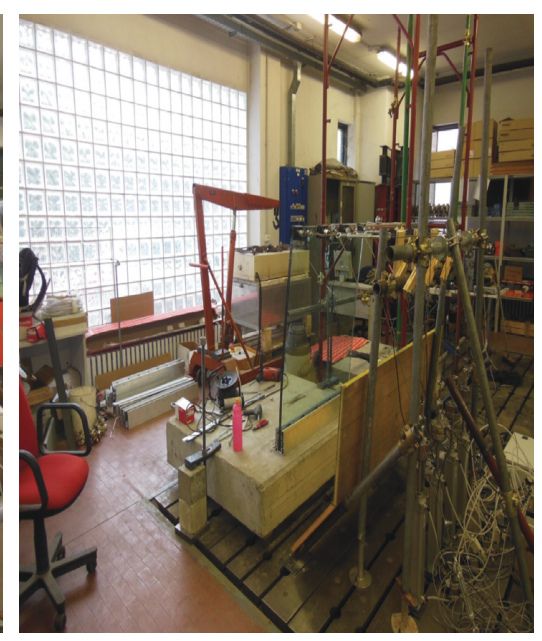

(a)
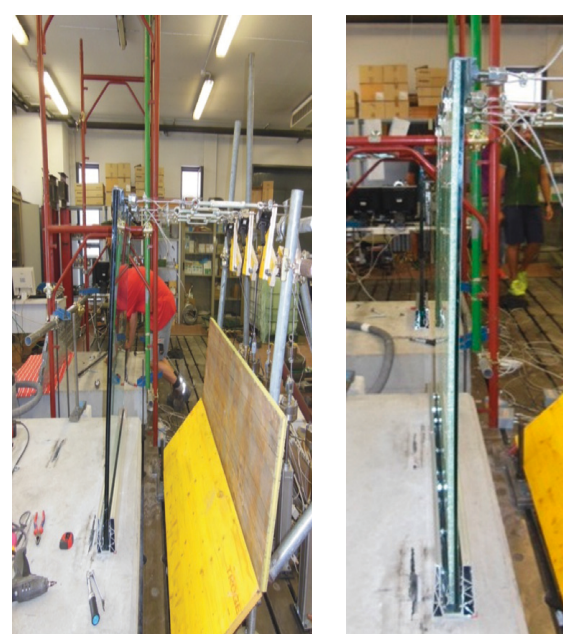

(b)

Figure 5: (a) Loaded specimens: NF4-8T-8I-PVB, NF4-10T-10I-PVB, and NF4-10T-10T-SG. (b) Damaged glass for the collapse limit state test on NF4-10T-10T-SG.

The results showed only marginal differences between the numerical results obtained with the initial mesh and the final one. Figure 8 shows a comparison of the experimental loaddisplacement curves (a) and of the numerical ones (b). As expected, the type of glass plays a fundamental role in the overall behavior; significant changes in stiffness and in residual displacement difference in deflection reading when loading and then unloading under flexure were observed. By introducing 5 clamps with a proper stiffness, it was possible to numerically simulate the experimentally observed behavior (Figure 8(b)).

The stress distribution at the ultimate state load level $(4.5 \mathrm{kN} / \mathrm{m}$; Figure 9(a)) shows that PVB interlayers lead to higher stresses around clamping with respect to SG (of about $140 \mathrm{MPa}$ versus $80 \mathrm{MPa}$ ), and the displacements were almost double. Similar behavior was observed for impact load (stress with impact on point 1 equal to $85.2 \mathrm{MPa}$ for $10 \mathrm{~T}$ 10I-PVB and 51.7 MPa for 10T-10T-SG, resp.).

Nonetheless, it is interesting to evaluate the effect of the clamping system on the overall behavior.

In particular, three parameters could be considered, namely, the number of clamps, their size, and their stiffness.

The clamps appears to be a significant parameter since by increasing their number, the peak stresses and the displacements reduce both under static and impact loads (Figures 10-12).

In any case, it seems that this parameter has a major influence when the glass panel is subjected to static loads. Indeed, as shown in Figure 13 the stresses plotted at a load level of $3 \mathrm{kN} / \mathrm{m}$ (ULS) as a function of the number of clamps have a dramatic reduction of about $55 \%$ (from about $180 \mathrm{MPa}$ with three clamps to about $80 \mathrm{MPa}$ with six clamps), while for impact tests, the stress reduction is only about $14 \%$.

Five clamps seem to be a good compromise to have low stresses under both static and impact loads.

By considering the ratio between the stress evaluated with clamps and the theoretical stress of a cantilever

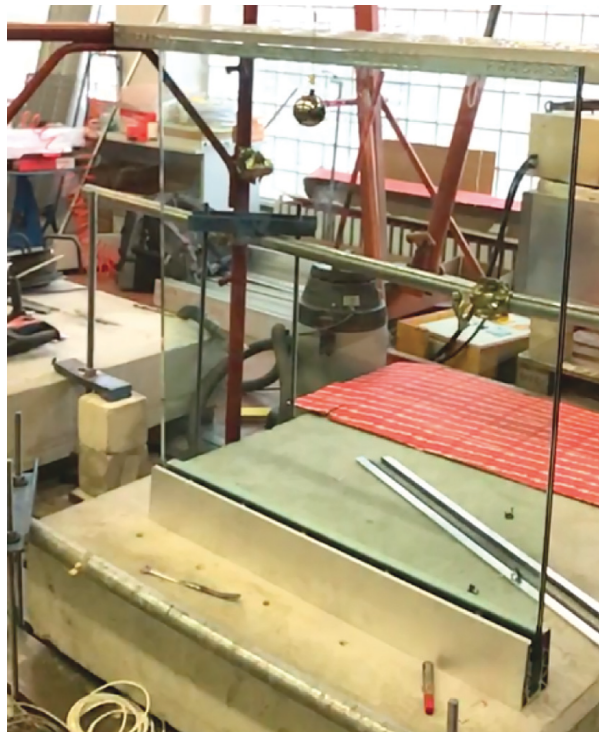

FIgURE 6: Hard body impact tests.

(evaluated according to the enhanced effective thickness (EET) method [27]; Figure 13), it results that six clamps well approach an uniform stress distribution, as shown in Figures 10 and 12, where it is evident that by increasing the number of clamps, the height of the area with a nonuniform stress distribution reduces.

The diameter of the clamps affects the stress field as well. Considering a diameter from $20 \mathrm{~mm}$ to $40 \mathrm{~mm}$ (actual diameter $30 \mathrm{~mm}$ ), the reduction of peak stresses is about $48 \%$ for static test and about 26\% for impact test (Figure 14(a)), respectively. With a diameter of the clamps of $40 \mathrm{~mm}$ (considering five clamps), the stress is very close to the stress in an ideal joint with uniform boundary conditions along the clamped edge (Figure 14(b)).

On the contrary, the stiffness of the clamps strongly affects the displacements (from about $98 \mathrm{~mm}$ to $198 \mathrm{~mm}$ for 


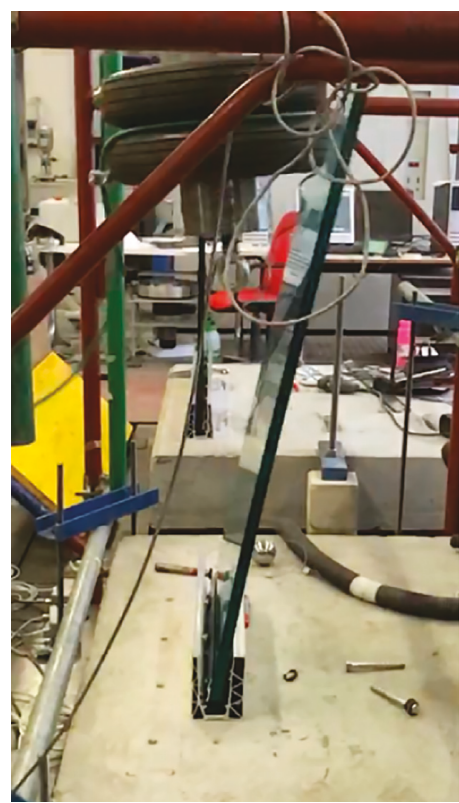

(a)

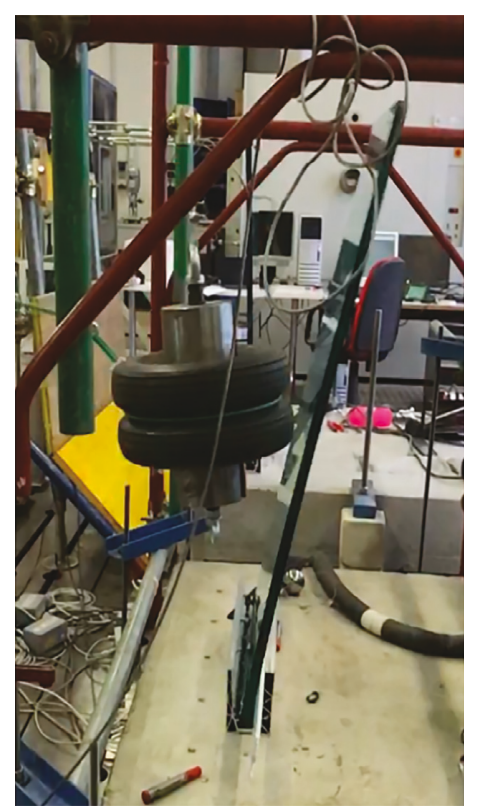

(b)

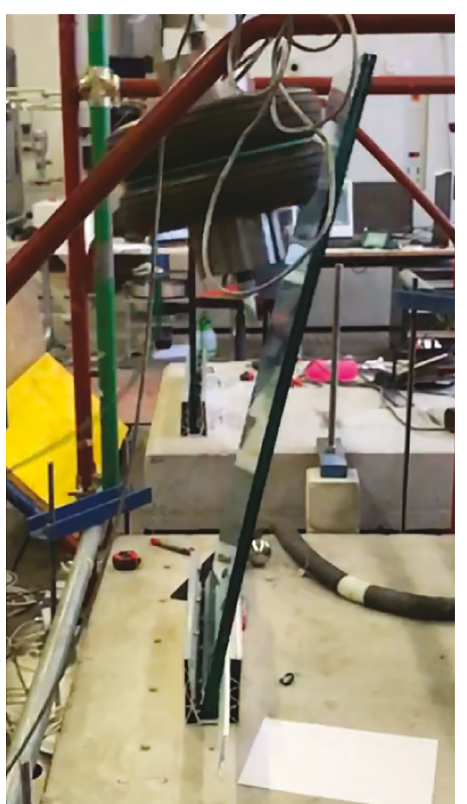

(c)

Figure 7: Specimen NF4-10T-10T-SG: impact points 1-2-3.

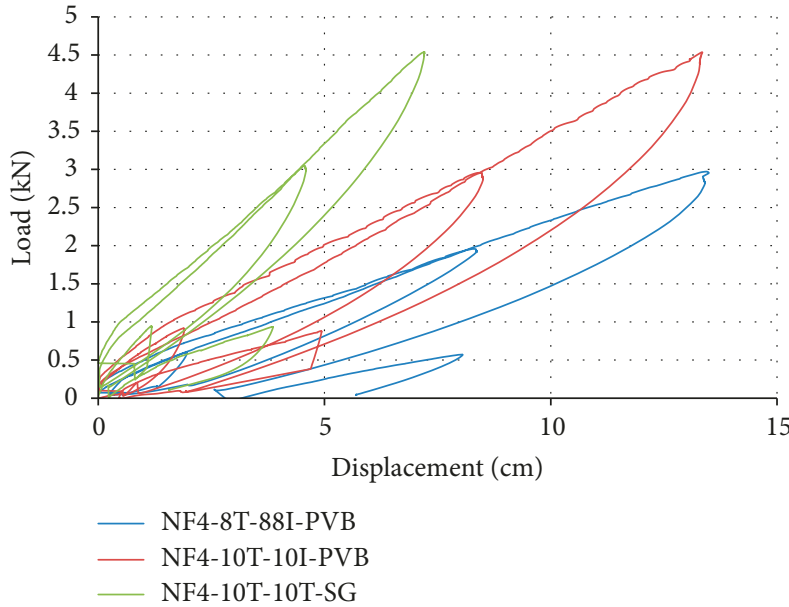

(a)

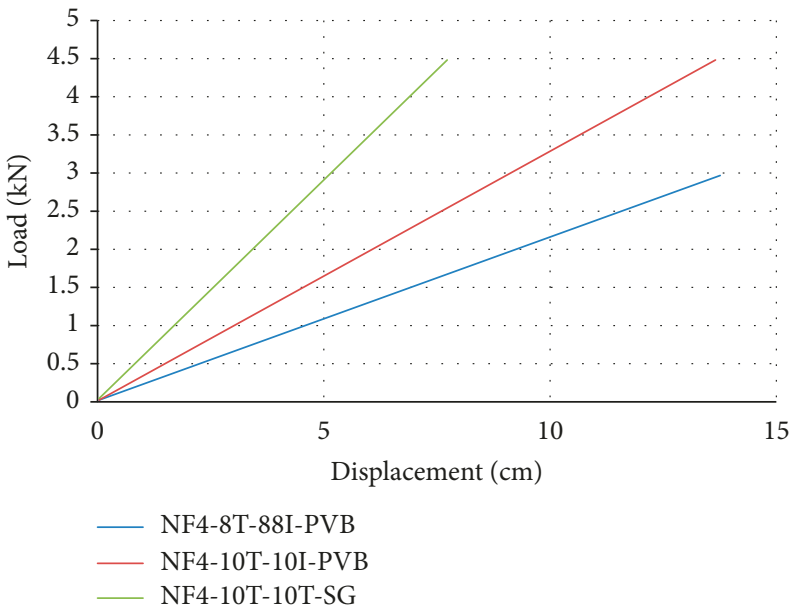

(b)

Figure 8: Load-displacement curves: (a) experimental; (b) numerical.

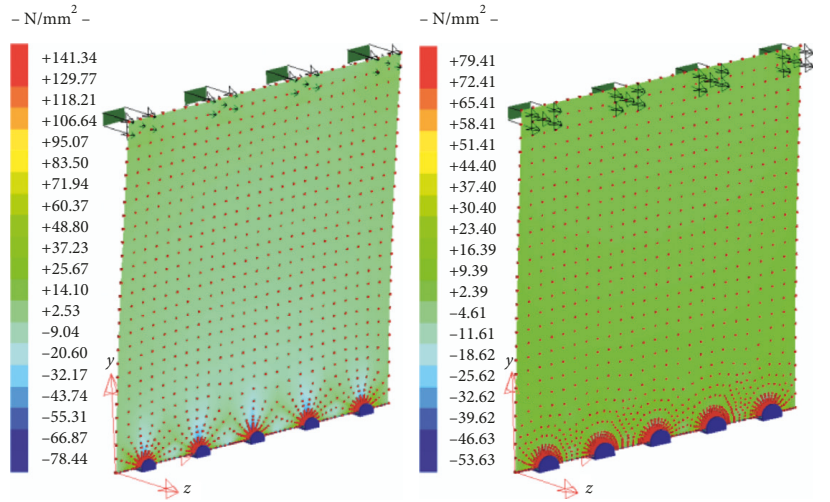

(a)

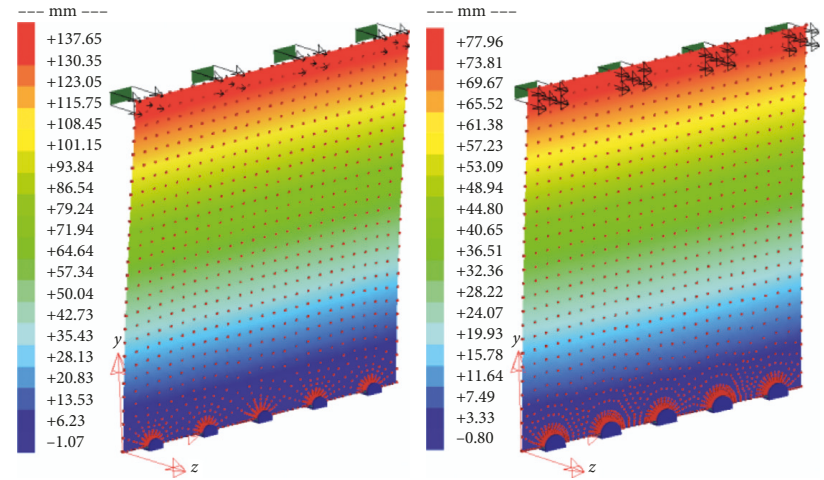

(b)

FIGURE 9: Comparison between stresses (a) and displacements (b) at the ultimate state limit (4.5 kN/m) of NF4-10T-10I-PVB versus NF4-10T-10T-SG. 


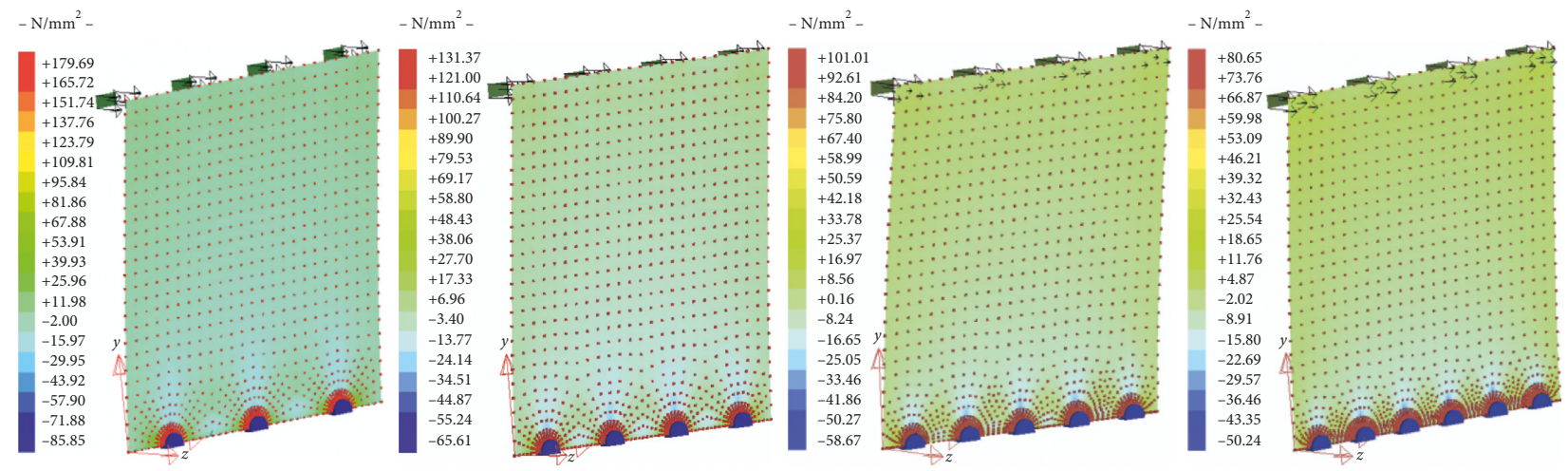

FIGURE 10: Stress distribution at the ultimate state limit $(3.0 \mathrm{kN} / \mathrm{m})$ with different numbers of clamps: glass $8 \mathrm{~T}+8 \mathrm{I}-\mathrm{PVB}$.
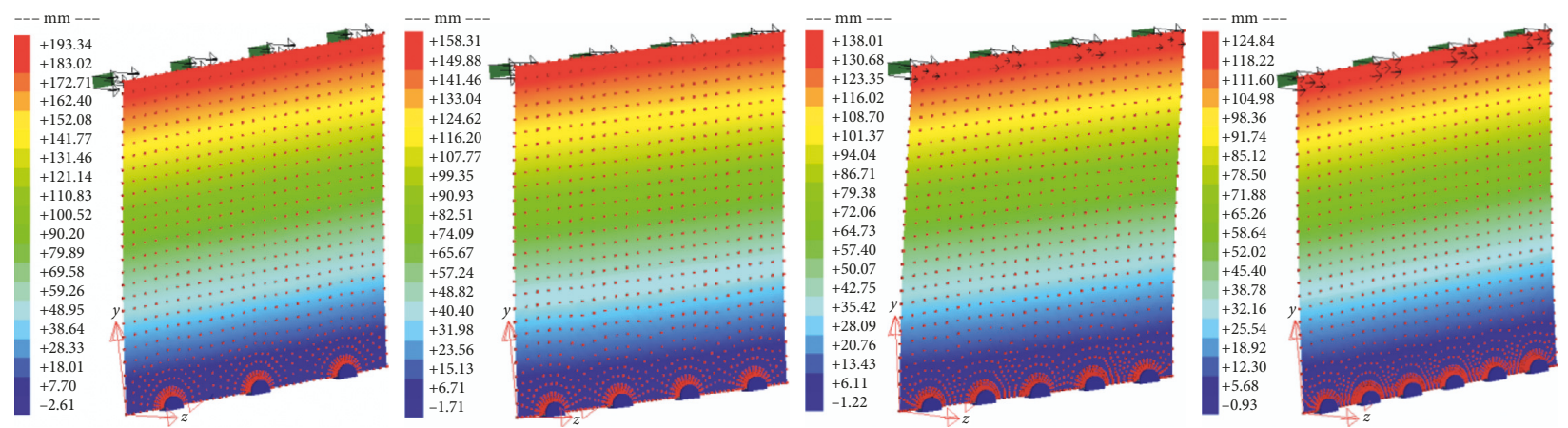

Figure 11: Displacement distribution at the ultimate state limit $(3.0 \mathrm{kN} / \mathrm{m})$ with different numbers of clamps: glass $8 \mathrm{~T}+8 \mathrm{I}$ PVB.
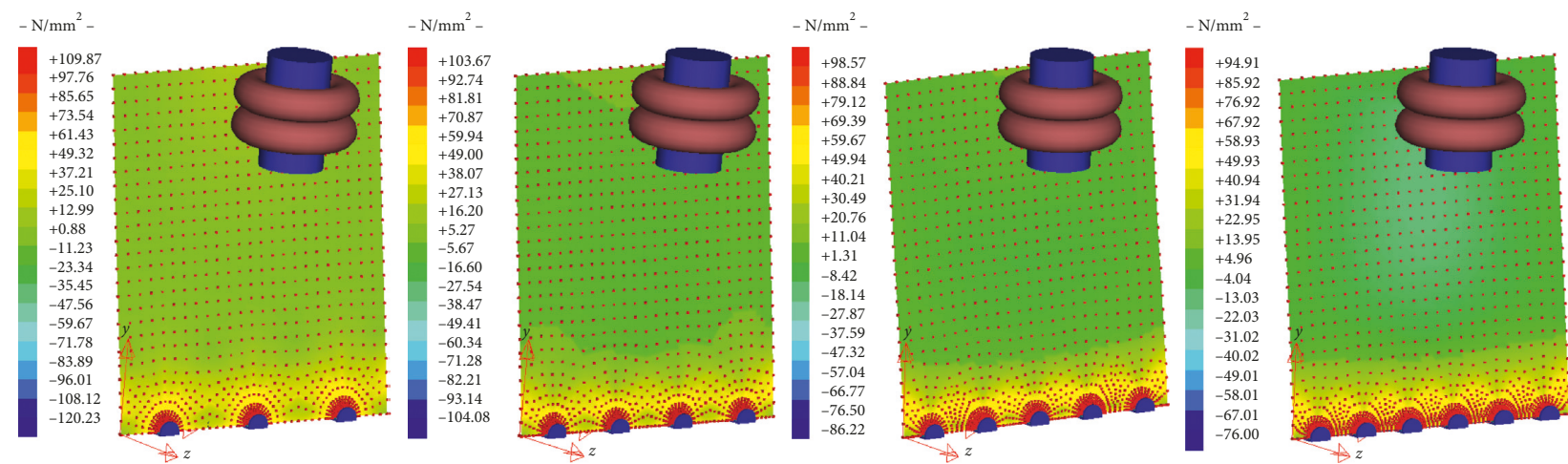

FIgURE 12: Stress distribution under impact load with different numbers of clamps: glass 8T + 8I PVB.

a rigid and a soft clamps, resp.) and the stresses under impact loads (from $80 \mathrm{MPa}$ to $120 \mathrm{MPa}$ for soft and rigid clamps, resp.) (Figure 15).

In conclusion, by increasing the number and the diameter of the clamps, stresses and displacements tend to reduce (for both type of test). On the contrary, by increasing the stiffness of the clamps, the displacements reduce but the stresses under impact loads rise.

It has to be noted that, in practical application, the number and the diameter of clamps have to be limited, and five clamps seem to meet the safety and economic requirements.

Indeed, it makes no sense to add clamps above a certain number (in this example, six) because the stresses approaches to a uniform stress distribution over the entire length and costs increase without safety benefits.

In the meantime, it should be noted that during impact tests, after each impact, the profile and the clamps damage, resulting in a reduced stiffness. This means that the first impact is crucial, while the second and the third impacts are affected by the reduced stiffness of the profile, turning up in a not so meaningful test.

\section{Conclusions}

The structural performance of cantilevered laminated glass plates using PVB and ionoplast SG interlayers subjected to 


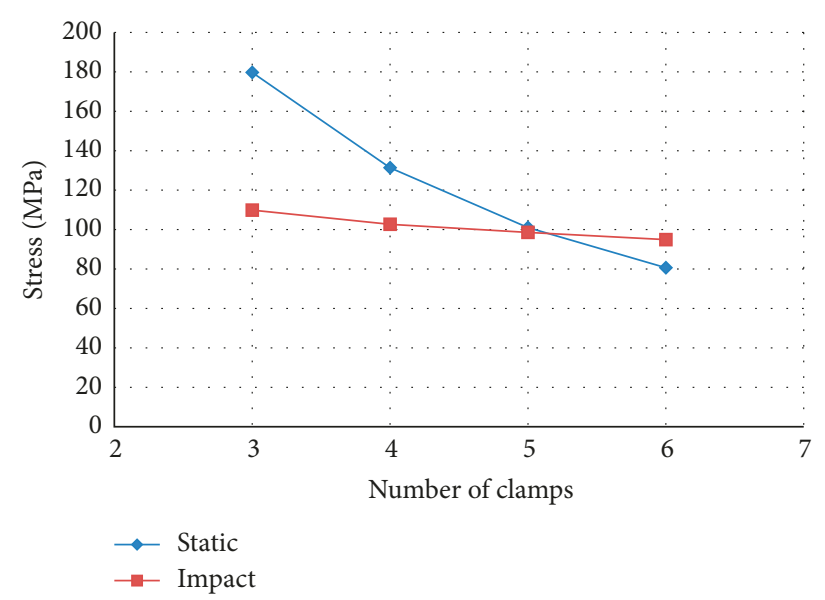

(a)

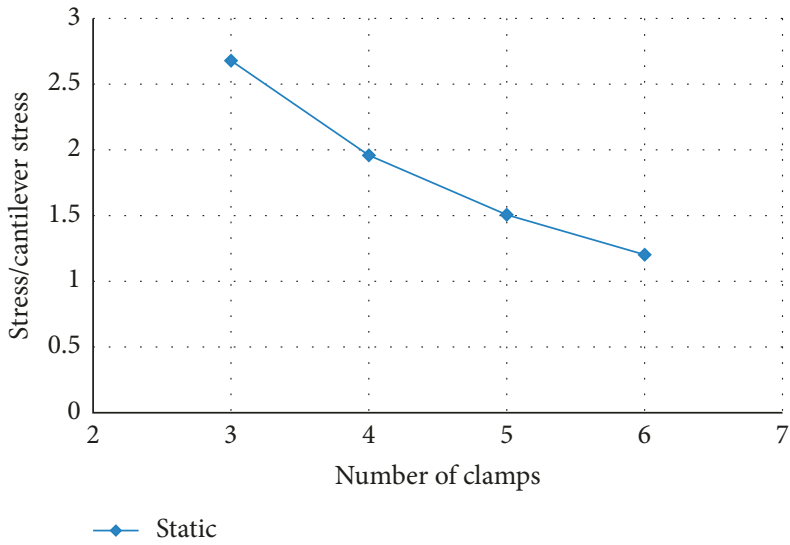

(b)

Figure 13: (a) Stress at the ultimate state limit $(3.0 \mathrm{kN} / \mathrm{m}$ (static)) and at impact and (b) ratio of the stress at the ultimate state limit $(3.0 \mathrm{kN} / \mathrm{m}$ (static) $)$ and the cantilever stress as a function of the different numbers of clamps: glass $8 \mathrm{~T}+8 \mathrm{I}$ PVB.

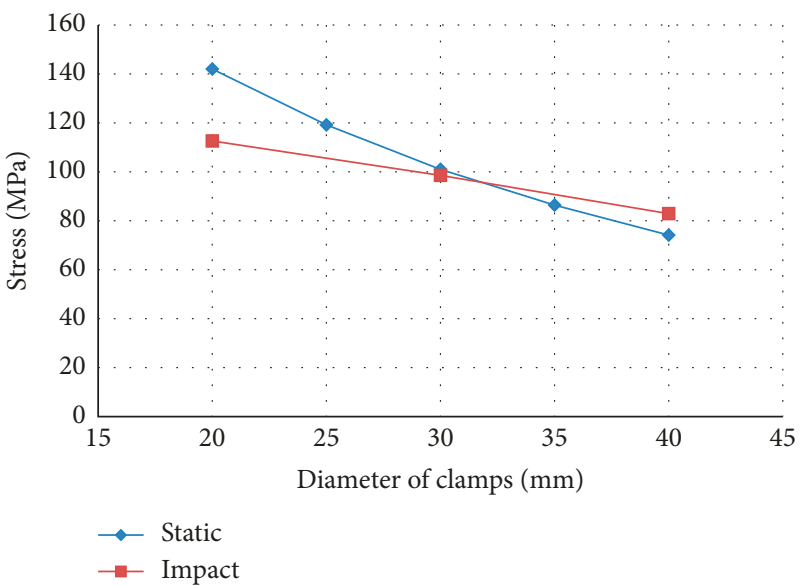

(a)

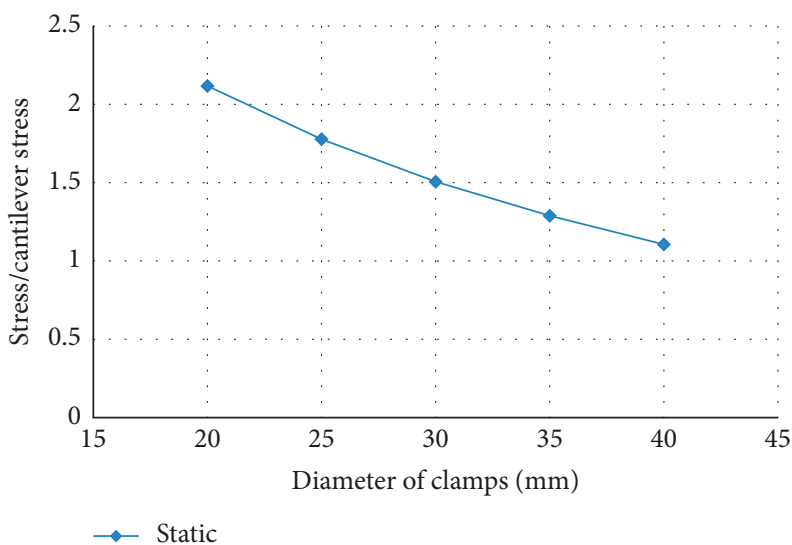

(b)

Figure 14: (a) Stress at the ultimate state limit $(3.0 \mathrm{kN} / \mathrm{m}$ (static)) and at impact and (b) ratio of the stress at the ultimate state limit $(3.0 \mathrm{kN} / \mathrm{m}$ (static)) and the cantilever stress as a function of the diameter of the clamps: glass $8 \mathrm{~T}+8 \mathrm{I}$ PVB.

static and impact loading was experimentally and numerically investigated.

Experimental evidence shows that the stiffness of interlayer (SG versus PVB) has a crucial effect on the overall behavior.

The numerical analysis highlights that the geometrical features of the constrained edge of the plate affect the stress concentrations and, as a consequence, the peak tensile stresses and therefore the structural strength of the balustrade.

In particular, the number of clamps, their size, and their stiffness are the most relevant factors that influence the elastic response.

By increasing the number and the diameter of the clamps, both static and impact tests show reduced stresses and displacements.

The stiffness of the clamps has a limited influence (for the considered range) on static test, although strongly affects the impact response. This means that during impact test, subsequent hits are meaningless because after the first impact, the stiffness of the clamps is strongly reduced.

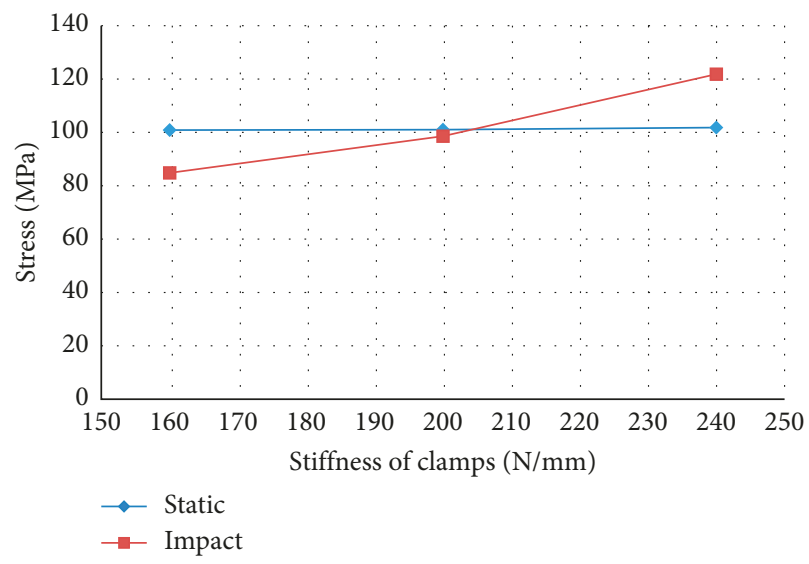

FIGURE 15: Stress at the ultimate state limit $(3.0 \mathrm{kN} / \mathrm{m})$ (static) and at impact as a function of the stiffness of the clamps: glass $8 \mathrm{~T}+8 \mathrm{I}$ PVB.

The number of clamps and the diameter could be limited because the stresses approach the uniform stress distribution over the entire length. 


\section{Data Availability}

The data used to support the findings of this study are available from the corresponding author upon request.

\section{Conflicts of Interest}

The authors declare that they have no conflicts of interest.

\section{Acknowledgments}

The authors would like to thank Faraone Srl which provided assistance for the experiments and the technical staff of the Materials and Structures Testing Laboratory at Politecnico di Milano, particularly Mr. Roberto Minerva and Mr. Daniele Spinelli for their assistance during the experimental work.

\section{References}

[1] J. Wurm, Glass Structures: Design and Construction of SelfSupporting Skins, Birkhauser Verlag AG, Basel, Switzerland, 2007.

[2] R. A. Behr, J. E. Minor, and H. S. Norville, "Structural behavior of architectural laminated glass," Journal of Structural Engineering, vol. 119, no. 1, pp. 202-222, 1993.

[3] E. Le Bourhis, Glass: Mechanics and Technology, Wiley-VCH Verlag, Weinheim, Germany, 2nd edition, 2014.

[4] W. A. Weibull, "Statistical distribution function of wide applicability," Journal of Applied Mechanics, vol. 18, no. 3, pp. 293-307, 1951.

[5] L. Biolzi, S. Casolo, V. Diana, and C. A. Sanjust, "Estimating laminated glass beam strength via stochastic Rigid Body-Spring Model," Composite Structures, vol. 172, pp. 61-72, 2017.

[6] E. Speranzini and S. Agnetti, "The technique of digital image correlation to identify defects in glass structures," Structural Control and Health Monitoring, vol. 21, no. 6, pp. 1015-1029, 2014.

[7] P. Foraboschi, "Experimental characterization of non-linear behavior of monolithic glass," International Journal of NonLinear Mechanics, vol. 67, pp. 352-370, 2014.

[8] P. Foraboschi, "Analytical modeling to predict thermal shock failure and maximum temperature gradients of a glass panel," Materials and Design, vol. 134, pp. 301-319, 2017.

[9] L. Biolzi, S. Cattaneo, and G. Rosati, "Progressive damage and fracture of laminated glass beams," Construction and Building Materials, vol. 24, no. 4, pp. 577-584, 2010.

[10] L. Biolzi, M. Orlando, L. Piscitelli, and P. Spinelli, "Static and dynamic response of progressively damaged ionoplast laminated glass beams," Composite Structures, vol. 157, pp. 337-347, 2016.

[11] S. J. Bennison, C. A. Smith, A. Van Duser, and A. Jagota, "Structural performance of laminated glass made with a "stiff" interlayer," in Proceedings of the 2001 Glass Performance Days, Tampere, Finland, June 2001.

[12] P. Foraboschi, "Optimal design of glass plates loaded transversally," Materials and Design, vol. 62, pp. 443-458, 2014.

[13] L. Biolzi, E. Cagnacci, M. Orlando, L. R. Piscitelli, and G. Rosati, "Long term response of glass-PVB double-lap joints," Composites Part B: Engineering, vol. 63, pp. 41-49, 2014.

[14] A. Kott and T. Vogel, "Safety of laminated glass structures after initial failure," Structural Engineering International, vol. 14, no. 2, pp. 134-138, 2004.

[15] L. Biolzi, S. Cattaneo, M. Orlando, L. Piscitelli, and P. Spinelli, "Post-failure behavior of laminated glass beams using different interlayers," Composite Structures, 2018, In press.
[16] K. Nehme, S. G. Nehme, and A. Jakab, "Impact behaviour of glass balustrades," in Proceedings of the Glass performance Days, pp. 350-355, Tampere, Finland, June 2015.

[17] D. Baraldi, A. Cecchi, and P. Foraboschi, "Broken tempered laminated glass: non-linear discrete element modeling," Composite Structures, vol. 140, pp. 278-295, 2016.

[18] L. Galuppi and G. Royer-Carfagni, "A homogenized analysis a la Hashin for cracked laminates under equi-biaxial stress. Applications to laminated glass," Composites Part B: Engineering, vol. 111, pp. 332-347, 2017.

[19] W. Stevels, "Design and testing of glass balustrade panels using a structural PVB interlayer," in Proceedings of the GlassCon Global Conference, pp. 297-303, Boston, MA, USA, July 2016.

[20] Italian Ministry Committee, D.M. 17 Gennaio 2018-Norme Tecniche per le Costruzioni, Italian Ministry Committee, Italy, 2018.

[21] UNI 11678, Glass in Building-Glass Infill Elements with Fall Protection Function-Resistance to Linear Static Load and Dynamic Load-Test Methods, UNI, Milan, Italy, 2017.

[22] EN 12600:2002, Glass in Building-Pendulum Test-Impact Test Method and Classification for Flat Glass, 2002.

[23] Regulation (EU) No. 305/2011 of the European Parliament and of the Council of 9 March 2011 Laying Down Harmonised Conditions for the Marketing of Construction Products and Repealing Council Directive 89/106/EEC Text with EEA Relevance, 2011.

[24] EOTA, EAD 090040-00-0404, Cantilevered Structural Glass Railing/Balustrade, 2016.

[25] European Commission JRC, CEN-TC 250 WG3, Guidelines for European Standard Structural Design of Glass Components, 2013.

[26] EOTA, TR048, Details of Tests for Post-Installed Fastener in Concrete, 2016.

[27] National Research Council of Italy Advisory Committee on Technical Recommendations for Construction, Guide for the Design, Construction and Control of Buildings with Structural Glass Elements, National Research Council of Italy Advisory Committee on Technical Recommendations for Construction, CNR-DT 210/2013, 2013. 


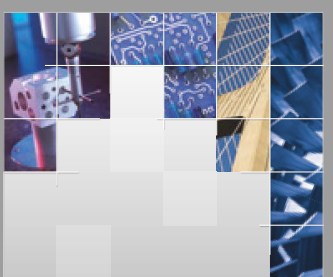

\section{Enfincering}
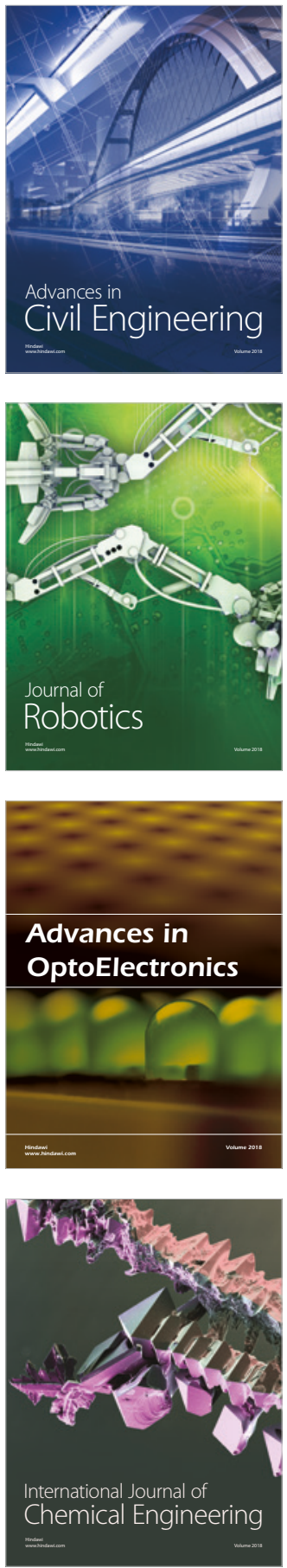

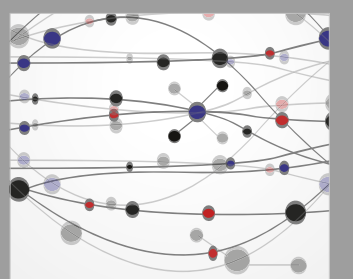

\section{Rotating \\ Machinery}

The Scientific World Journal

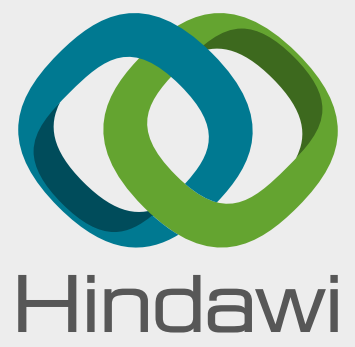

Submit your manuscripts at

www.hindawi.com
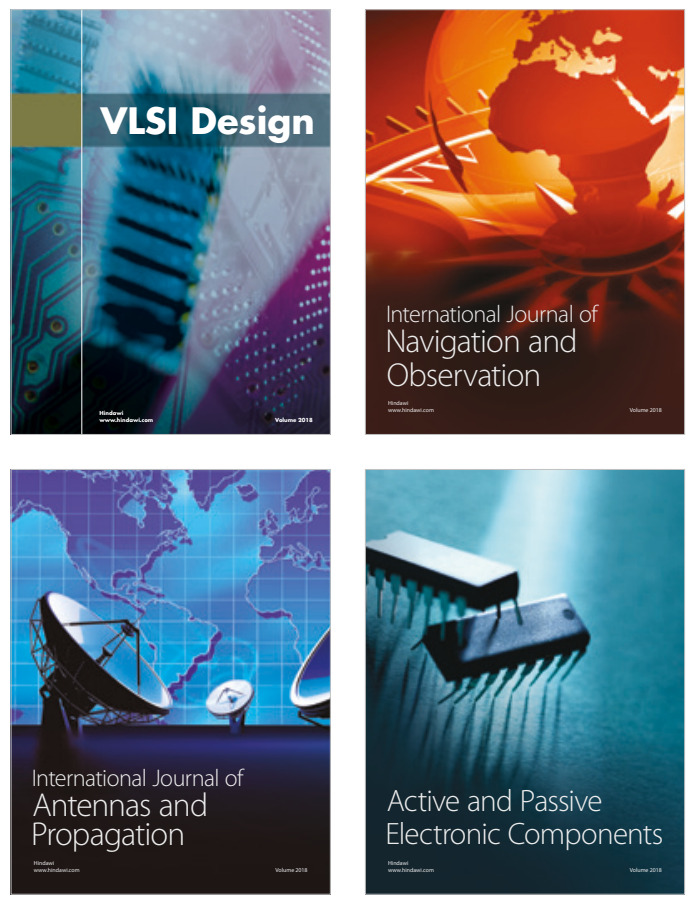
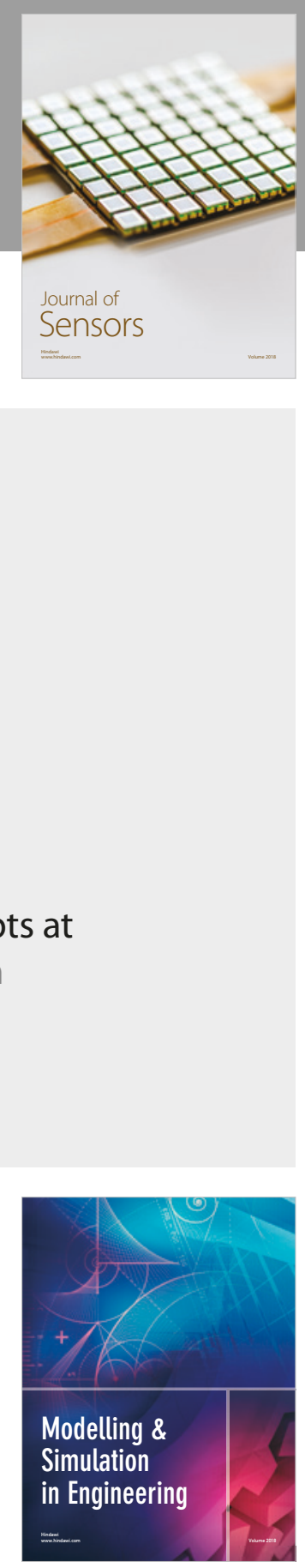

\section{Advances \\ Multimedia}
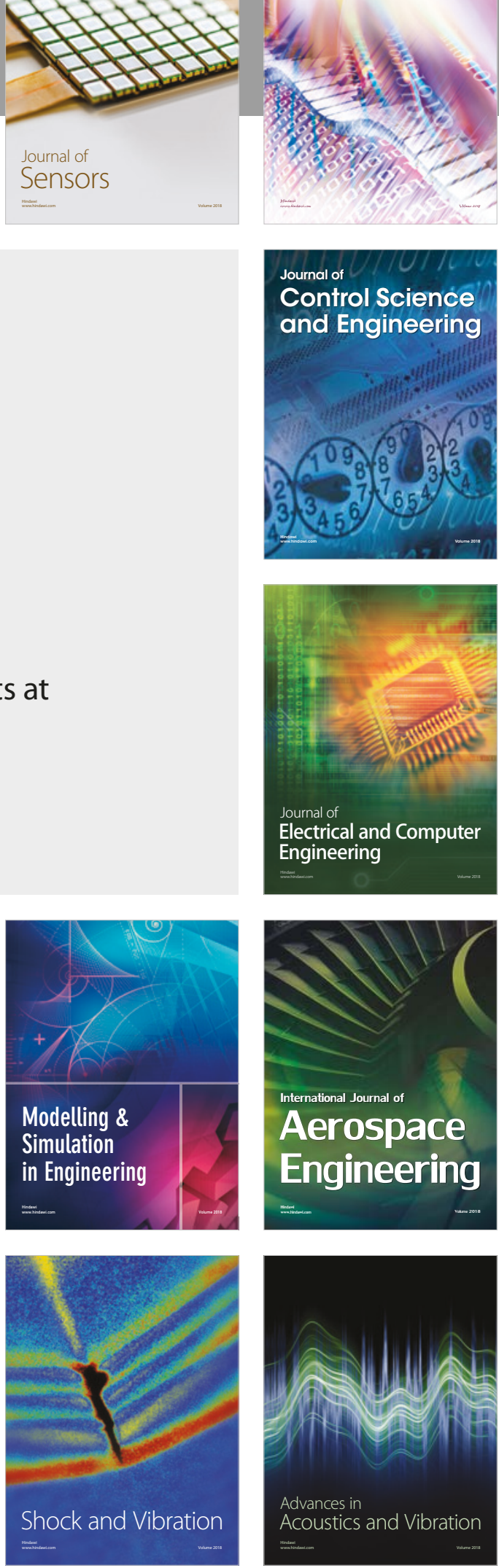